\title{
Optimization of Product Design to Reduce Environmental Impact of Machining
}

\author{
Zahari Taha \\ University Malaysia Pahang Pahang, Malaysia \\ E-mail: zaharitaha@ump.edu.my \\ Julirose Gonzales $^{\dagger}$ \\ University Malaya Kuala Lumpur, Malaysia \\ E-mail: juli_gonzales@siswa.um.edu.my ${ }^{1}$ \\ Novita Sakundarini \\ University Malaya Kuala Lumpur, Malaysia \\ E-mail: novitas73@yahoo.com \\ Raja Ariffin Raja Ghazila \\ University Malaya Kuala Lumpur, Malaysia \\ E-mail: rajaariffin@gmail.com
}

\section{Salwa Abdul Rashid}

Received, January 4, 2011; Revised, April 6, 2011; Accepted, May 13, 2011

\begin{abstract}
This paper presents a study on product design optimization to reduce the environmental impact of machining. The objective is to analyze the effect of changing the product design parameters such as its dimensions, and basic features on the environmental impact of machining process in terms of its energy consumption, waste produced and the chemicals and other consumables used up during the process. To realize this objective, we used a CAD model of a product with different design scenarios, and analyze their energy consumption using an environmental impact calculator method developed. The waste produced, and the consumables used up, such as lubricants and coolants were analyzed using environmental emission factors. Optimization methods using Genetic Algorithm and Goal Programming are applied to the product design parameters in order to get the best possible product dimensions with the least environmental impact of the machining process.
\end{abstract}

Keywords: Eco-Design, Life Cycle Inventory, Life Cycle Design, CAD/CAM

\section{INTRODUCTION}

The growing environmental awareness of today's consumers has put the manufacturing companies with the burden of taking responsibility for their own product's environmental impact. To ease the manufacturer's burden, different environmental concepts were developed scoping from a product/technological point of view to an organizational perspective.

In lieu of the recent UN Climate Change Conference in Copenhagen 2009, one of the objectives of the Copenhagen Accord (UNFCC, 2009) is to maintain the maximum temperature rise to less than $2^{\circ} \mathrm{C}$. With this, government and industrial sectors are starting to count their $\mathrm{CO}_{2}$ emissions and outlining ways to reduce their impacts. In the manufacturing sector, initiatives like Eco-design, Design for the Environment, Design for Recyclability, Green Supply Chain, Reverse Logistics, Product Stewardship, and/or Product Take-back have been initiated in developed countries such as Japan, Australia and European countries. Strategic measures and initiatives by the government and industries in developing countries on the other hand, are still at infancy level. Based on a pilot study on the implementation of eco design among Malaysian companies (Taha, et al., 2008), it was revealed that soft regulatory controls, 
awareness and lack of supportive infrastructure have led to the unwillingness of Malaysian industry in initiating eco design. Since Malaysian industries are still grappling with the idea of eco design, supportive infrastructure is needed. Malaysian clean production efforts are still end pipe activities which do not consider design as the element of change.

Evaluation methods on the environmental impact of machining methods and optimization of machining processes are available however, in a designer's point of view the environmental impact of a manufacturing process is not assessed in the planning and conceptual development stages of product design. The need to consider the potential impact of a design in early stage of its development would be beneficial in terms of time and cost. Since in the planning and conceptual stage there is no actual manufacturing of a prototype product, an assessment tool needs to be developed which is based on information that is available to the designers during these design stages: Material to be used, functional characteristics, basic geometrical features and the manufacturing process that it will undergo.

A gate to gate environmental impact of a product can be assessed by combining those information mentioned that are known to the designer with their corresponding material and process life cycle inventory (LCI) data from a database. With this, the impact of different design scenarios can be quickly assessed.

\section{SYSTEM OVERVIEW}

The goal of this system, as shown in figure 1 , is to analyze the potential environmental impact of the machining process based on limited product design information, and generate an optimized design solution to reduce the potential environmental impact of a specific product design. It consists of an assessment, database, computation, and an improvement block. During the conceptual to embodiment design stage, minimum information about the design is available, with basically just major features and their dimensions. The system starts from the design input, where the design features like holes, pocket, chamfer, slots, etc; and their dimensions are identified. From the design information provided, machining parameters like cutting speed, feed rate and machining time can be generated from basic machining formula, or from CAM software calculation, or direct input from the designer.

In the assessment block, the machining strategies are evaluated in terms of the amount of power consumption, lubricant oil quantity, coolant quantity, and the amount of chip removed, which are the contributing factors to the environmental impact of a machining process. The database block contains the life cycle inventory (LCI) of the environmental impact contributing factors, and the cutting tool parameters for the estimation of the machining process. This research is con- cerned with a gate to gate analysis only and life cycle inventory data dealt with is only within the scope of the machining process and the disposal of its wastes. Data from other impact factors like overhead (energy consumption of lights, air conditioning, transport, etc.) are not considered in this research since these data are not dependent on the product design, thus having a constant value, even with varying design scenarios.

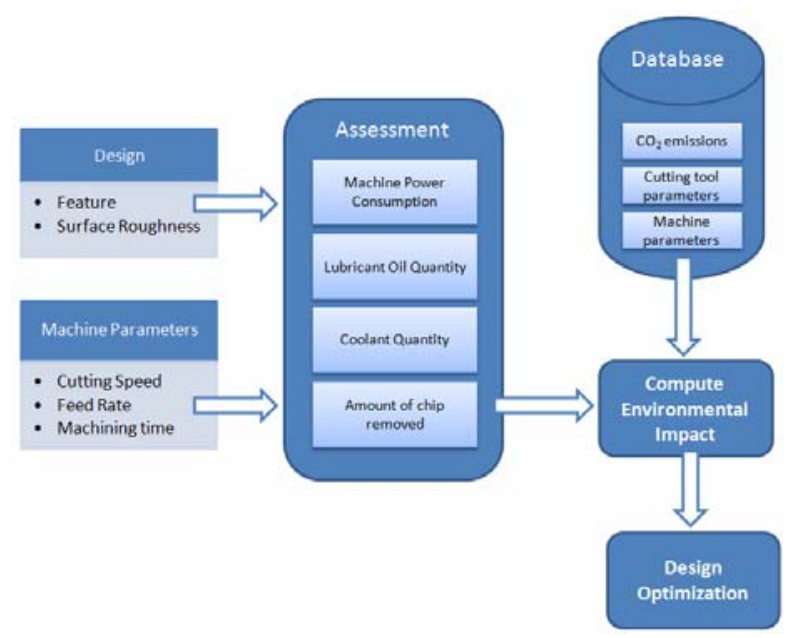

Figure 1. Proposed System Overview.

The computation block calculates the potential amount of environmental impact of the design. A detailed discussion on the computation of these impact factors will be discussed in the third section of this paper. The improvement block invokes the optimization algorithm to generate the optimum design scenario.

Feature-based analysis is done in this system, wherein each value of impact is computed for each design feature. This provides detailed impact information, thus making it easy to identify which particular feature would be the biggest impact contributor. Once the features with the biggest impact are identified, designers could focus on the specific features so that they could improve the design and eventually reduce the environmental impact.

Normally, LCA impacts are categorized according to the types of emissions to the environment: from global warming, ozone layer depletion, human toxicity, energy resource depletion, and the like. This study focuses on the global warming potential (GWP) as an environmental impact. GWPs allow scientists and policymakers to compare the ability of each greenhouse gas to trap heat in the atmosphere relative to other gases. GWP of a greenhouse gas is the ratio of radiative forcing, from $1 \mathrm{~kg}$ of greenhouse gas, to $1 \mathrm{~kg}$ of $\mathrm{CO}_{2}$ over a hundred years. $\mathrm{CO}_{2}$ was chosen as a reference gas to be consistent with the Intergovernmental Panel on Climate Change (IPCC) (Forster, 2007).

The improvement block uses optimization methods to find the optimum design scenario by providing a range of allowable design dimensions for each feature that 
could be modified and combined together to get a final optimal product with the least environmental impact.

\section{COMPUTATION OF POTENTIAL ENVI- RONMENTAL IMPACT}

The total equivalent $\mathrm{CO}_{2}$ emission (potential environmental impact) is calculated from the power consumption of the machine, lubricant and coolant oil consumption, and the amount of chip removed during the machining process by analyzing the machining operations for each feature. The general equation to compute potential environmental impact for each feature is shown in Eq. (1).

$$
\mathrm{Ei}=\mathrm{PMi}+\mathrm{Ci}+\mathrm{Li}+\mathrm{Chi}
$$

Ei: Potential Environmental impact $\left(\mathrm{kg}-\mathrm{CO}_{2}\right)$

PMi: Machine power consumption impact

Ci: Coolant consumption impact

Li: Lubricant oil consumption impact

Chi: Chip recycling impact

To compute the machining power consumption impact PMi as shown in Eq. (2), the feed rate and spindle speed of the machining operation for each feature is needed in order to determine the feed and spindle motor power respectively. Table 1 shows the respective feed motor and spindle motor power consumption for varying feed rate and spindle speed taken from experiments by (Arakawa, 2007). For other peripheral devices of the machine like NC Controller, and coolant pump, these are calculated from their running times.

$$
\mathrm{PMi}=\mathrm{LCI}(\mathrm{e}) \times\left(\mathrm{PSm}+\mathrm{PFm}+\sum \mathrm{PP}\right)
$$

PMi: Machine power consumption impact $\left(\mathrm{kg}-\mathrm{CO}_{2}\right)$

$\mathrm{LCI}(\mathrm{e}): \mathrm{CO}_{2}$ emission intensity of electricity (kg$\left.\mathrm{CO}_{2} / \mathrm{kWh}\right)$

PSm: Power consumption of spindle motor (kWh)

PFm: Power consumption of feed motor (kWh)

PP: Power consumption of peripheral devices

The coolant is stored in a tank and it uses a pump to supply to the cutting point during machining. It is then flushed back to the storage tank after use and then reused again after being separated from the chips. Some coolant may evaporate due to the heat in the cutting tool, or adhere to the metal chips little by little. Therefore, coolant needs to be replenished, mixed with water to compensate for the loss. Computation of the coolant consumption impact $\mathrm{Ci}$, is shown in Eq. (3) below.

$$
\begin{aligned}
\mathrm{Ci}= & {[\{\mathrm{LCI}(\mathrm{cp})+\mathrm{LCI}(\mathrm{cd})\} \times \mathrm{Tc}+\mathrm{LCI}(\mathrm{w}) \times \mathrm{Tw}] } \\
& \times \mathrm{Ct} / \mathrm{MTTR}
\end{aligned}
$$

$\mathrm{LCI}(\mathrm{cp}): \mathrm{CO}_{2}$ emission intensity of coolant production $\left(\mathrm{kg}-\mathrm{CO}_{2} / \mathrm{L}\right)$

$\mathrm{LCI}(\mathrm{cd}): \mathrm{CO}_{2}$ emission intensity of coolant disposal $\left(\mathrm{kg}-\mathrm{CO}_{2} / \mathrm{L}\right)$

Tc: Total amount of coolant (initial coolant quantity + coolant replenishment quantity, L)

$\mathrm{LCI}(\mathrm{w}): \mathrm{CO}_{2}$ emission intensity of water distribution $\left(\mathrm{kg}-\mathrm{CO}_{2} / \mathrm{L}\right)$

Tw: Total amount of water (initial quantity + replenishment quantity, L)

Ct: Cutting time (s)

MTTR: Mean time to replenish coolant (s)

Lubricant oil is used for the slideway, spindle, hydraulic unit, rotary table and double arm changer for the tool magazine. Lubricant application may vary from different kinds of machines, but a general formula to compute the impact would require the running time of the moving parts, the mean interval of lubricant discharges, amount of lubricant discharged and the emission intensity of the lubricant production and disposal, as shown in Eq.(4) below.

$$
\mathrm{Li}=\mathrm{Lrt} / \mathrm{MTTD} \times \mathrm{Ld} \times(\mathrm{LCI}(\mathrm{lp})+\mathrm{LCI}(\mathrm{ld}))
$$

Lrt: Running time of moving parts (s)

MMTD: Mean time to discharge lubricant (s)

Ld: Amount of lubricant discharged (L)

$\mathrm{LCI}(\mathrm{lp})$ : $\mathrm{CO}_{2}$ emission intensity of lubricant production $\left(\mathrm{kg}-\mathrm{CO}_{2} / \mathrm{L}\right)$

LCI(ld): $\mathrm{CO}_{2}$ emission intensity of lubricant disposal $\left(\mathrm{kg}-\mathrm{CO}_{2} / \mathrm{L}\right)$

The last part of the equation deals with the amount of impact by the metal chip removed from the workpiece by machining. These chips are recycled in an electrical heating furnace to be melted and re-sold again in various forms. Recycling these chips causes environmental impact because of the electric consumption on furnace use. Impact values are dependent on the type of metal and its weight $\left(\mathrm{kg}-\mathrm{CO}_{2} / \mathrm{kg}\right)$ so determining the total weight of the chips removed is the key component, as shown in Eq. (5).

$$
\mathrm{Chi}=(\mathrm{WpV}-\mathrm{PV}) \times \mathrm{d} \times \mathrm{LCI}(\mathrm{m})
$$

WpV: Workpiece volume $\left(\mathrm{cm}^{3}\right)$

PV: Product volume $\left(\mathrm{cm}^{3}\right)$

d: material density $\left(\mathrm{kg} / \mathrm{cm}^{3}\right)$

$\mathrm{LCI}(\mathrm{m}): \mathrm{CO}_{2}$ emission intensity of metal chip recycling $\left(\mathrm{kg}-\mathrm{CO}_{2} / \mathrm{kg}\right)$

\section{CASE STUDY}

To demonstrate the application of the proposed system, a case study is conducted on a machined rod bracket with 3 different design scenarios. 
Stock Size: $5 \times 4 \times 2$ in $=40 \mathrm{in}^{3}$

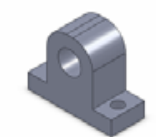

Design 1

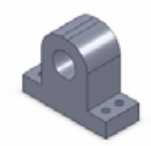

Design 2

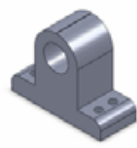

Design 3

\begin{tabular}{c|c|c|c}
\hline Feature Specifications & Design 1 & Design 2 & Design 3 \\
\hline \hline Screw holes & $2 \times 21 / 32$ & $4 \times 25 / 64$ & $4 \times 25 / 64$ in \\
\hline Over-all area covered y screws & 0.6824 in2 & 0.47784 in2 & 0.47748 in2 \\
\hline Fillet & top & top & top and sides \\
\hline Rod hole diameter & 1.375 in & 1.375 in & 1.375 in \\
\hline Product Volume & 21.15 in 3 & 21.32 in 3 & 19.1 in 3 \\
\hline Wall thickness & 0.6875 in & 0.6875 in & 0.5125 in \\
\hline
\end{tabular}

Figure 2. Comparison of 3 rod bracket designs.

The computation of the environmental impact for each feature for each design follows the general computation formula from section 3. In this case study, the set of machine and tool parameters of V33 Makino Machine Co. Ltd. (Arakawa, et al., 2007) are used with the details shown in Tables 1 and 2 below.

Table 1. Electric power consumption components.

\begin{tabular}{|c|c|c|}
\hline \multicolumn{2}{|c|}{ Unit Name } & Power Consumption (kW) \\
\hline \multirow{6}{*}{$\begin{array}{l}\text { Spindle } \\
\text { Motor }\end{array}$} & $5000[\mathrm{rpm}]$ & $\begin{array}{c}0.25 \\
\end{array}$ \\
\hline & $10000[\mathrm{rpm}]$ & 0.75 \\
\hline & $15000[\mathrm{rpm}]$ & 1.35 \\
\hline & $20000[\mathrm{rpm}]$ & 2.15 \\
\hline & $25000[\mathrm{rpm}]$ & 3.1 \\
\hline & $30000[\mathrm{rpm}]$ & 4.5 \\
\hline \multirow{4}{*}{$\begin{array}{l}\text { Feed } \\
\text { Drive } \\
\text { Motor }\end{array}$} & $200[\mathrm{~mm} / \mathrm{min}]$ & 0.02 \\
\hline & $1000[\mathrm{~mm} / \mathrm{min}]$ & 0.1 \\
\hline & $2000[\mathrm{~mm} / \mathrm{min}]$ & 0.2 \\
\hline & $5000[\mathrm{~mm} / \mathrm{min}]$ & 0.5 \\
\hline \multicolumn{2}{|c|}{ Cooling System of Spindle } & 2.05 \\
\hline \multicolumn{2}{|c|}{ Coolant pump } & 0.96 \\
\hline \multicolumn{2}{|c|}{ Lubrication Pump } & 0.15 \\
\hline \multicolumn{2}{|c|}{ Chip Conveyor } & 0.2 \\
\hline \multicolumn{2}{|c|}{ NC Controller } & 0.24 \\
\hline
\end{tabular}

Table 2. Other parameters to compute environmental impact.

\begin{tabular}{c|c}
\hline \multicolumn{2}{c}{ Lubricant } \\
\hline \hline mean interval between supply & $6 \mathrm{mos}$ \\
\hline lubricant oil qty supplied & $500 \mathrm{~mL}$ \\
\hline lubricant production & 0.469 \\
\hline lubricant disposal & 0.0029 \\
\hline Coolant & $18 \mathrm{~L}$ \\
\hline Initial coolant qty & $9 \mathrm{~L}$ \\
\hline Coolant replenishment qty & $30 \mathrm{~L}$ \\
\hline Total amount of water & $2 \mathrm{mos}$ \\
\hline Mean time to replenish coolant
\end{tabular}

The $\mathrm{CO}_{2}$ emissions used for this case study where compiled from different LCI database tables and Embodiment Energy Emission Inventory Data (3EID) by (Narita, et al., 2006) summarized at Table 3 below.

Table 3. $\mathrm{CO}_{2}$ emissions involved in Machining.

\begin{tabular}{c|c}
\hline \multicolumn{2}{c}{$\mathrm{CO}_{2}$ emissions } \\
\hline Electricity $\left(\mathrm{kg}-\mathrm{CO}_{2} / \mathrm{kWh}\right)$ & 0.381 \\
\hline Coolant production $\left(\mathrm{kg}-\mathrm{CO}_{2} / \mathrm{L}\right)$ & 0.9776 \\
\hline Coolant disposal $\left(\mathrm{kg}-\mathrm{CO}_{2} / \mathrm{L}\right)$ & 0.0029 \\
\hline Lubricant production $\left(\mathrm{kg}-\mathrm{CO}_{2} / \mathrm{L}\right)$ & 0.469 \\
\hline Lubricant disposal $\left(\mathrm{kg}-\mathrm{CO}_{2} / \mathrm{L}\right)$ & 0.0029 \\
\hline Metal chip recycling $\left(\mathrm{kg}-\mathrm{CO}_{2} / \mathrm{kg}\right)$ & 0.0634 \\
\hline Water Production $(\mathrm{kg}-\mathrm{CO} / \mathrm{L})$ & 0.189
\end{tabular}

The machining of the three designs may vary in strategies, and result to different machining times. However, the research is focused on feature-based analysis and machining time is assessed per feature. Therefore, if the parts would be having the same feature and dimensions, it is assumed that they will have equal machining times. The machining time can be computed using the basic machining formula from machining handbooks (Oberg, et al., 2004) Using the product dimensions in this case study as shown in Figure 2, the environmental impact is computed and shown in Table 4 below.

Table 4. $\mathrm{CO}_{2}$ emissions of the product designs.

\begin{tabular}{c|c|c|c}
\hline $\begin{array}{c}\text { CO2 emissions } \\
(\mathrm{kg}-\mathrm{CO} 2)\end{array}$ & Design 1 & Design 2 & Design 3 \\
\hline $\begin{array}{c}\text { Feed motor and } \\
\text { spindle motor }\end{array}$ & 0.0041 & 0.0058 & 0.0060 \\
\hline $\begin{array}{c}\text { Peripheral electric } \\
\text { consumption of }\end{array}$ & 0.0854 & 0.1183 & 0.1226 \\
\hline Lubricant oil & 0.0000029 & 0.0000040 & 0.0000041 \\
\hline Coolant & 0.001160 & 0.001608 & 0.001666 \\
\hline Metal chip & 0.131081 & 0.139167 & 0.158218 \\
\hline Total & 0.2220 & 0.2650 & 0.2890 \\
\hline
\end{tabular}

Based on the results from table 4 , the amount of metal chip is the greatest contributor to the $\mathrm{CO}_{2}$ emissions for all designs. Since design 3 has the smallest over-all volume and the most chips removed (assuming they were all cut from the same size of stock), it has the highest value of $\mathrm{CO}_{2}$ emissions among the three designs. The environmental impact $\mathrm{CO}_{2}$ emission was computed from the summation of the $\mathrm{CO}_{2}$ emissions of each machined feature. Given that the amount of metal chip is the greatest contributor to the impact, it is easy to identify which feature from the design could be improved in order to reduce the potential impact. 


\section{OPTIMIZATION RESULTS DISCUSSION}

Each design has features that would have specific dimensions based on the product requirements. Most of these dimensions would be within a given range and designers would play around these limited values to find the optimal value. For this case study, the assumption for the dimension limitations (min-max design limits) for each feature is taken from the designer's set of allowable values for the dimensions based on his initial assessment of the product. This initial assessment already took into consideration the customer's functional requirement of the product. Customer's functional requirement may include cost and product functionality such as compressive stress. With the basic requirements already satisfied, the designer can further improve the product by reducing its potential environmental impact by optimizing the product dimensions within the design limits as shown in Table 5. The goal is to find the optimal design values within the limit that would result to a low environmental impact. To solve this problem, two types of optimization methods are tested.

The first and most direct method is goal programming using Generalized Reduced Gradient (GRG) algorithm to find the optimum value for a single objective.
With this method, the single objective considered for this case study is the total environmental impact of each design (Design 1, 2 and 3). So the optimization was run once for each design and the result only shows a single set of design dimensions per design that would have the least amount of environmental impact. The result, is the set of minima values from the design limits because it follows the thought of, the lesser machining time would result to a lesser impact. The beauty of this method is the fast computation of the optimized value. However, when the optimization is run several times, the results are not consistent and far from the expected optimized value. A non-linear problem may have more than one feasible region where all constraints are satisfied. Within the feasible region, there is a possibility of more than 1 peak (maxima) or valley (minima), and there is no general method to determine the highest peak or lowest valleys within this feasible region. Because of these possible solutions, there are few guarantees to find the "true" optimal solution. Also, this algorithm follows a path from the starting values to the final solution values, which will stop at a peak or valley closest to the starting values supplied, thus the reason for inconsistent results.

The second method tested is Genetic Algorithm (GA), which performs a global search for the maxima

Table 5. Design Limits and Optimization Results using Genetic Algorithm.

\begin{tabular}{|c|c|c|c|c|c|c|c|c|}
\hline \multirow[b]{2}{*}{ Design 1} & \multicolumn{5}{|c|}{ Design Limits } & \multicolumn{2}{|c|}{ Optimization results } & \multirow[b]{2}{*}{ no. of available solutions } \\
\hline & Min & Max & A & $\mathrm{B}$ & $\mathrm{C}$ & no. of available solutions & $\mathrm{D}$ & \\
\hline Rod Hole & 1.30 & 1.40 & 1.30 & 1.39 & 1.30 & 8 & 1.40 & 21 \\
\hline Screw Hole & 0.25 & 0.70 & 0.25 & 0.69 & 0.25 & 6 & 0.70 & 1 \\
\hline Fillet & 0.39 & 1.57 & 0.39 & 0.70 & 0.39 & 7 & 0.79 & 1 \\
\hline Outercut area & 3.30 & 5.20 & 3.30 & 3.53 & 3.30 & 2 & 3.61 & 1 \\
\hline \multicolumn{9}{|l|}{ Design 2} \\
\hline Rod Hole & 1.30 & 1.40 & 1.30 & 1.32 & 1.30 & 5 & 1.40 & 7 \\
\hline Screw Hole & 0.25 & 0.70 & 0.25 & 0.30 & 0.25 & 9 & 0.40 & 4 \\
\hline Fillet & 0.39 & 1.57 & 0.39 & 0.55 & 0.34 & 4 & 0.88 & 2 \\
\hline Outercut area & 3.30 & 5.20 & 3.30 & 3.96 & 3.30 & 10 & 3.61 & 1 \\
\hline \multicolumn{9}{|l|}{ Design 3} \\
\hline Rod Hole & 1.30 & 1.40 & 1.30 & 1.39 & 1.30 & 10 & 1.40 & 4 \\
\hline Screw Hole & 0.25 & 0.40 & 0.25 & 0.26 & 0.25 & 10 & 0.40 & 4 \\
\hline Fillet 1 & 0.39 & 1.57 & 0.39 & 0.85 & 0.39 & 2 & 0.89 & 3 \\
\hline Fillet 2 & 0.39 & 0.79 & 0.39 & 0.63 & 0.39 & 7 & 0.77 & 2 \\
\hline Outercut area & 3.30 & 5.20 & 3.30 & 3.36 & 3.30 & 19 & 3.54 & 1 \\
\hline
\end{tabular}

Column A shows the design set with the lowest possible sum of its dimensions.

Column B shows the design set with highest possible sum of its dimensions.

Column $\mathrm{C}$ shows the lowest possible dimension for each feature along with the number of identical design sets that uses this dimension.

Column D shows the highest possible dimension for each feature along with the number of identical design sets that uses this dimension. 
(or minima) values using iterative methods, thus making the computing time longer. The initial optimization run with the goal set to finding the minimum environmental impact resulted to a population of 200 design sets all having the same value of the minimum design limits. This strongly suggests that there is only 1 solution for the lowest environmental impact. To try to utilize the robustness of GA, the goal is changed to find the design sets that are within at least $90 \%$ reduction of environmental impact (with $100 \%$ as lowest possible environmental impact based on the design limitations). With this new goal, the resulting population yielded a wide range of varying design sets combination and still within a low environmental impact value (though not the minima). Table 5 shows the results using GA, summarized showing the highest and lowest possible design dimension for each feature. Given this variety of results, this allows more design choices for the designer to choose from, especially in the cases where there are priority features that needs to be satisfied. For example, the designer is looking for a particular design set, with the least possible environmental impact and with the biggest possible dimension for the rod hole based on the given limitations and constraints. So using column $\mathrm{D}$, the designer can see that there are 21 possible design combinations (for design 1) that can be chosen from and from there, the environmental impact value can be sorted and choose the one with the lowest impact.

\section{CONCLUSION}

To conclude this paper, there are two findings. First, in machining operation, the design that would have less machining time and amount of material removed would have the least environmental impact. So when it came to the optimization of the design, the resulting parameter values are near to the spectrum of the minimum value based on the allowable range. If that is always the case, then the designer would always tend to just use the minimum possible values without the use of optimization, which comes to the second finding. In designing for sustainability, there are other factors to consider besides the environmental impact of a product. The economic value and the social value of the product must also be considered, which is the motivation for future (or rather on-going) work.

This paper also shows the difference of the proposed method from traditional assessment methods.
The proposed method uses the amount of material removed and machining time as the primary contributors to the environmental impact, while the traditional manufacturing assessment methods use the over-all volume of the product to determine the environmental impact. Though there are differences in the techniques used, the method proposed shows a more realistic approach on the assessment of the environmental impact as its basis is the actual amounts of the contributing factors.

\section{REFERENCES}

Forster, P., Ramaswamy, V. et al. (2007), Changes in Atmospheric Constituents and in Radiative Forcing. In: Climate Change 2007: The Physical Science Basis. Contribution of Working Group I to the Fourth Assessment Report of the Intergovernmental Panel on Climate Change. Cambridge University Press, Cambridge, United Kingdom and New York, NY, USA. Chapter 2, 210.

Arakawa, Yuki, Aoyama, Hideki (2007), Basic Study on Development of System to Determine Machining Conditions for Minimizing Energy Consumed in Machine Tool. The 4th International Conference on Leading Edge Manufacturing in 21st Century. Fukuoka, Japan. Nov. 7-9, 2007.

Taha, Sukandirini, Ariffin, R. (2000), Implementation of Design for Environment in Indonesia and Malaysia Industries: A Survey. Proceeding Asia Pasific Industrial Engineering and Management Systems, Bali, Indonesia.

Available Online: Copenhagen Accord (2009), http:// unfccc.int/files/meetings/cop_15/application/pdf/co p15_cph_auv.pdf.

Narita, H., Kawamura, H., Norihisa, T., Chen, L., Fujimoto, H., and Hasebe, T. (2006), "Development of Prediction System for Environmental Burden for Machine Tool Operation (1st Report, Proposal of Calculation Method for Environmental Burden)," Japan Society of Mechanical Engineers: International Journal, Series C, 49(4), 1188-1195.

Oberg, E., Jones, F., Horton, H., and Ryffel, H. (2004), Machinery's handbook, Industrial Press New York.

Bicik, J., Morley, M., and Savi, D. (2008), A Rapid Optimization Prototyping Tool for Spreadsheet Based Models, ASCE. 